\title{
A multicenter review of deep venous thrombosis prophylaxis practice patterns for blunt hepatic trauma Indraneel Datta1 ${ }^{1}$ Chad G Ball*1, Lucas R Rudmik1, Damian Paton-Gay², Deepak Bhayana ${ }^{3}$, Peter Salat ${ }^{4}$, Colin Schieman ${ }^{1}$, Dean F Smith ${ }^{3}$, Mary vanWijngaarden-Stephens ${ }^{2}$ and John B Kortbeek ${ }^{1}$
}

\author{
Address: ${ }^{1}$ Department of Surgery, University of Calgary, Calgary, Canada, ${ }^{2}$ Department of Surgery, University of Alberta, Edmonton, Canada, \\ ${ }^{3}$ Department of Radiology, University of Calgary, Calgary, Canada and ${ }^{4}$ Department of Radiology, University of Alberta, Edmonton, Canada \\ Email: Indraneel Datta - idatta@ucalgary.ca; Chad G Ball* - ball.chad@gmail.com; Lucas R Rudmik - luke.rudmik@albertahealthservices.ca; \\ Damian Paton-Gay - patongay@ualberta.ca; Deepak Bhayana - deepak.bhayana@albertahealthservices.ca; \\ Peter Salat - peter.salat@calgaryhealthregion.ca; Colin Schieman - colin.schieman@gmail.com; \\ Dean F Smith - dean.smith@calgaryhealthregion.ca; Mary vanWijngaarden-Stephens - mary.stephans@albertahealthservices.ca; \\ John B Kortbeek - john.kortbeek@albertahealthservices.ca \\ * Corresponding author
}

Published: 3 June 2009

Journal of Trauma Management \& Outcomes 2009, 3:7 doi:10.1186/1752-2897-3-7
Received: 6 March 2009

Accepted: 3 June 2009

This article is available from: http://www.traumamanagement.org/content/3/1/7

(C) 2009 Datta et al; licensee BioMed Central Ltd.

This is an Open Access article distributed under the terms of the Creative Commons Attribution License (http://creativecommons.org/licenses/by/2.0), which permits unrestricted use, distribution, and reproduction in any medium, provided the original work is properly cited.

\begin{abstract}
Background: Non-operative management of blunt hepatic trauma is successful in the majority of hemodynamically stable patients. Due to the risk of recurrent hemorrhage, pharmacologic deep venous thrombosis (DVT) prophylaxis is often delayed. The optimal timing of prophylaxis is unclear. A multi-centre, retrospective review of patients with blunt hepatic injuries presenting between 2000 and 2004 was performed. All patients had an ISS $\geq 12$ and a CT scan confirming hepatic trauma. Patients were categorized into: (I) early DVT prophylaxis ( $\leq 48 \mathrm{hrs}$ of admission), (2) delayed prophylaxis (>48 hrs), and (3) no prophylaxis.
\end{abstract}

Methods and results: Thirty-seven (25\%) and $45(42 \%)$ patients received early and delayed DVT prophylaxis respectively. The remainder $(32 \%)$ received none. Mean hepatic injury grades were lower in the early prophylaxis group (II) compared to the delayed and no prophylaxis cohorts (III)(P $=0.002$ ). The number of patients requiring post-admission blood transfusions was highest in the delayed group (44\%) compared to the early $(26 \%)$ and no prophylaxis $(6 \%)$ groups $(p=0.03)$. No patient in the early prophylaxis cohort developed a DVT or required delayed angiographic or operative intervention. Two patients in the delayed group failed non-operative management. Eight (18\%) patients in the delayed group developed a clinically significant DVT; I (2\%) progressed to a PE.

Conclusion: Practice patterns indicate that chemical DVT prophylaxis initiated within 48 hours of admission may be safe in patients with significant blunt hepatic trauma. Delays in prevention result in venothromboembolic events, but not in fewer blood transfusions or a decreased need for subsequent angiographic or operative therapies. 


\section{Background}

Hepatic trauma complicates $25 \%$ of all blunt injuries [1]. Modern management of these patients depends primarily upon their hemodynamic stability and concurrent pattern of injury. Recent series identify that $98 \%$ of all stable patients, regardless of injury grade, can be successfully managed without an operative procedure [2].

Deep venous thrombosis (DVT) is a common complication. The observed incidence among trauma patients exceeds $50 \%$ when thromboprophylaxis is omitted [3]. Geerts and colleagues demonstrated that low molecular weight heparins (LMWH) significantly reduce the incidence of DVT compared to unfractionated heparin (UH), with rates of $7 \%$ and $15 \%$ respectively [4]. As a result, enoxaparin has become the standard pharmaceutical agent for DVT prophylaxis in multisystem trauma patients. In spite of its benefit, surgeons often delay the initiation of chemical DVT prophylaxis in those with blunt hepatic trauma due to the potential risk of recurrent bleeding. When coupled with the pathophysiology of multisystem injuries, which often include pelvic and head trauma, this delay places patients at an increased risk for DVT formation.

The optimal timing of DVT prophylaxis for blunt hepatic injured patients is unclear. The purpose of this study was to (1) identify the usage pattern of DVT prophylaxis in non-operative patients with blunt hepatic injuries among high volume trauma facilities, and (2) compare the outcomes of patients with early versus delayed initiation of chemical DVT prophylaxis.

\section{Methods}

A multi-institutional (University of Alberta and Foothills hospitals), retrospective review of all patients with blunt hepatic injuries occurring between October, 2000 and October, 2004 was performed. The data was extracted from the province-wide Alberta Trauma Registry (ATR). This registry prospectively collects data on all patients sustaining a severe injury (Injury Severity Score (ISS) $=12$ ) within the province of Alberta. The ATR also possesses detailed information describing the mechanism of injury, patient injuries, all therapies, and inpatient outcomes. This database has been internally validated to be $98 \%$ accurate [5].

The ethics review committees at the Universities of Calgary and Alberta approved the study protocol. Inclusion criteria included patients with an ISS $\geq 12$ and a computed tomography (CT) scan confirming blunt hepatic injury. Patients were excluded if they had a penetrating liver injury, intracranial hemorrhage, or died within 24 hours of admission. They were also excluded if they underwent operative or angiographic intervention within 24 hours of admission.
Two staff radiologists, experienced in trauma imaging, completed blinded individual reviews of all patient CT imaging. Hepatic injuries were re-graded using the American Association for the Surgery of Trauma liver injury scale [6]. Both radiologists were blinded to the initial admitting radiological interpretation. Patients were then divided into three groups based on the timing of pharmacologic DVT prophylaxis. "Early" patients received DVT prophylaxis within 48 hours; "delayed" patients received prophylaxis after 48 hours; and the final group received no DVT prophylaxis during their hospital admission. DVTs were diagnosed by clinical suspicions confirmed by ultrasound imaging. Pulmonary emboli (PE) were diagnosed via thoracic CT. All compression stockings were sequential pneumatic devices. Study endpoints included post-admission blood transfusions (packed red blood cells (pRBC)), post-admission angiographic embolization, non-operative failure, DVT formation, and the rate of PE.

Statistical analysis was performed using Stata version 8.0 (Stata Corp. College Station, Texas, USA). Normally or near-normally distributed variables were reported as means and non-normally distributed variables as medians. Differences were demonstrated using ANOVA and Student t-tests. A p value less than 0.05 was considered to represent statistical significance for all comparisons.

\section{Results}

During the study period, 390 patients were diagnosed with a hepatic injury. One hundred and six (27\%) met the study inclusion criteria (Table 1). No patients died. DVT prophylaxis was administered in the early and delayed cohorts in 25\% (27/106) and 42\% (45/106) respectively. Thirty-four (32\%) additional patients received no pharmacologic DVT prophylaxis. Demographics and initial hemodynamic measurements were similar between all groups (Table 1). There was a higher rate of blood transfusions in the delayed cohort $(24 \%)$, compared to the early and no DVT prophylaxis groups (11\% and $12 \%$ respectively) $(\mathrm{p}=0.03)$. The mean ISS was also higher in the delayed group when compared to the no prophylaxis cohort $(\mathrm{p}=0.02)$.

The mean hepatic injury grades were lower in the early prophylaxis group (2.2) compared to either the delayed or no prophylaxis cohorts (2.9 and 3 respectively) $(\mathrm{p}=$ $0.002)$. Most $(70 \%)$ patients in the early group were comprised of lower grade injuries (I, II). The majority of patients in the delayed group (78\%) had higher injury grades (III, IV, V) (Table 1). Post-admission hemoglobin levels were stable across all cohorts $(\mathrm{p}=0.47)$ (Table 2). The mean hospital length of stay (LOS) was highest in the delayed prophylaxis group (26 days), followed by the early and no prophylaxis groups (14 and 8 days respectively) $(\mathrm{p}=0.0003)$ (Table 2$)$. The delayed group also pos- 
Table I: Patient demographics and injuries

\begin{tabular}{|c|c|c|c|}
\hline Variable & Early & Delayed & None \\
\hline Total & 27 & 45 & 34 \\
\hline Mean Age & 37 & 42 & 30 \\
\hline Gender (\% male) & 63 & 78 & 59 \\
\hline Mean ISS & 22 & 25 & 20 \\
\hline Mean Number of Injuries & 7 & 9 & 5 \\
\hline Mean Admission Blood Pressure & 130 & 124 & 128 \\
\hline Mean Admission Heart Rate & 93 & 97 & 89 \\
\hline Blood Transfusion (\%) & 11 & 22 & 12 \\
\hline Mean Number of Blood Units & 2 & 3 & 2.5 \\
\hline Mean Admission Hemoglobin & 127 & 121 & 126 \\
\hline \multicolumn{4}{|l|}{ Hepatic Injury Grade: } \\
\hline Mean & 2.2 & 2.9 & 3.0 \\
\hline Grade I & $6 / 27(22 \%)$ & $6 / 45(13 \%)$ & I/34 (3\%) \\
\hline Grade 2 & $13 / 27(48 \%)$ & $4 / 45(9 \%)$ & $9 / 34(25 \%)$ \\
\hline Grade 3 & $5 / 27(19 \%)$ & $24 / 45(54 \%)$ & $14 / 34(42 \%)$ \\
\hline Grade 4 & $3 / 27(11 \%)$ & $9 / 45(20 \%)$ & $9 / 34(26 \%)$ \\
\hline Grade 5 & 0 & $2 / 45(4 \%)$ & I/34 (3\%) \\
\hline
\end{tabular}

ISS = Injury Severity Score

sessed the highest rate of ICU admission (44\%), with an associated mean LOS of 9 days, while the no prophylaxis cohort required ICU care in only $9 \%$ of patients. Pharmacologic DVT prophylaxis was most commonly initiated on post admission day 1 for the early group and day 6 for the delayed group (Table 2). LMWH was used in $78 \%$ of patients in the early group and $84 \%$ of patients in the delayed cohort. UH was employed in the remainder.

Overall, the delayed group experienced the highest rate of post-admission blood transfusions (44\%) when compared to both the early and no prophylaxis groups (26\% and $6 \%$ respectively)(Table 3 ). There were no delayed

Table 2: Inpatient demographics

\begin{tabular}{llll}
\hline Variable & Early & Delayed & None \\
\hline Total & 27 & 45 & 34 \\
Mean Hemoglobin (PAD 2) & 109 & 98 & 118 \\
Mean Hemoglobin (PAD 5) & 104 & 105 & 116 \\
Mean Length of Hospital Stay (days) & 14 & 26 & 8 \\
ICU Admission (\%) & 22 & 44 & 9 \\
Mean length of ICU Stay (days) & 8 & 9 & 3 \\
Mean PAD Ambulation Allowed & 3 & 6 & 4 \\
Use of Compression Stockings (\%) & 44 & 91 & 71 \\
Mean PAD DVT Prophylaxis Started & 1 & 6 & - \\
LMWH (\%) & 78 & 84 & - \\
\hline Unfractionated Heparin (\%) & 22 & 16 & - \\
\hline
\end{tabular}

PAD $=$ Post Admission Day

$I C U=$ Intensive Care Unit

DVT = Deep Venous Thrombosis

LMWH = Low Molecular Weight Heparin arterial embolizations or non-operative management failures in the early and no prophylaxis groups. In the delayed prophylaxis group however, 2 patients failed nonoperative observation. Both suffered grade 5 injuries. One of these patients also underwent pre-operative arterial embolization. No DVT or PE was diagnosed in the early or no prophylaxis groups. Eight (18\%) patients were diagnosed with a DVT in the delayed group, with one $(2 \%)$ patient developing a clinically significant PE.

The early and delayed prophylaxis groups were also delineated based on grade of injury (Table 4 and Table 5). There was no increase in the rates of post-admission blood transfusion, arterial embolization, or non-operative failure in patients with low grade (Grade I and II) injuries who received early pharmacologic DVT prophylaxis. There was however, 1 DVT $(10 \%)$ diagnosed in a

Table 3: Patient outcomes

\begin{tabular}{llll}
\hline Variable & Early & Delayed & None \\
\hline Total & 27 & 45 & 34 \\
Blood Transfusion Post-Admission(\%) & 26 & 44 & 6 \\
Mean Number of Blood Units & 2.6 & 4.3 & 1.5 \\
Arterial Embolization (\%) & 0 & 2 & 0 \\
Failure of Non-operative Therapy(\%) & 0 & 4 & 0 \\
Deep Venous Thrombosis (\%) & 0 & $8 / 45(18)$ & 0 \\
$\quad$ LMWH Group (\%) & 0 & $4 / 8(50)$ & 0 \\
Pulmonary Embolus (\%) & 0 & $1 / 45(2)$ & 0 \\
\hline LMWH Group (\%) & 0 & $0 / 1(0)$ & 0 \\
\hline
\end{tabular}

LMWH = Low Molecular Weight Heparin 
Table 4: Comparison of early and delayed prophylaxis group outcomes for grade $I$ and 2 hepatic injuries

\begin{tabular}{lll}
\hline Variable & Early & Delayed \\
\hline Total & 19 & 10 \\
Mean ISS & 21 & 22 \\
Mean Length of Hospital Stay (days) & 11 & 24 \\
ICU Admission (\%) & 16 & 60 \\
Mean PAD DVT Prophylaxis Started & 1 & 6 \\
Blood Transfusion Post-Admission(\%) & 26 & 40 \\
Mean Number of Blood Units & 2.6 & 4 \\
Arterial Embolization (\%) & 0 & 0 \\
Failure of Non-operative Therapy(\%) & 0 & 0 \\
Deep Venous Thrombosis (\%) & 0 & $1 / 10(10)$ \\
\hline Pulmonary Embolus (\%) & 0 & 0
\end{tabular}

ISS = Injury Severity Score

$I C U=$ Intensive Care Unit

PAD $=$ Post Admission Day

DVT $=$ Deep Venous Thrombosis

patient with a low grade injury with delayed DVT prophylaxis. Although the ISS $(\mathrm{p}=0.53)$ and mean number of injuries $(\mathrm{p}=0.26)$ were similar between both cohorts, the delayed group had a higher ICU admission rate (60\% versus $16 \%$ respectively), and hospital LOS (24 versus 11 days respectively) ( $\mathrm{p}=0.0069)$.

In patients with high grade hepatic injuries, only 8 received early pharmacologic DVT prophylaxis (Table 5 ). These groups had a similar ISS $(\mathrm{p}=0.90)$ and mean number of injuries $(\mathrm{p}=0.13)$. The ICU admission rate and hospital LOS were also similar between the early and delayed groups $(\mathrm{p}=0.71)$. Two patients (grade 5 injuries) failed non-operative observation. Overall 8 (18\%) DVTs and $1(2 \%)$ PE were diagnosed in patients who had a delay in pharmacologic DVT prophylaxis.

Table 5: Comparison of early and delayed prophylaxis group outcomes for grades 3, 4 and 5 hepatic injuries

\begin{tabular}{lll}
\hline Variable & Early & Delayed \\
\hline Total & 8 & 35 \\
Mean ISS & 26 & 25 \\
Mean Length of Hospital Stay (days) & 23 & 27 \\
ICU Admission (\%) & 38 & 37 \\
Mean PAD DVT Prophylaxis Started & 1 & 6 \\
Blood Transfusion Post-Admission(\%) & 25 & 46 \\
Mean Number of Blood Units & 2 & 4 \\
Arterial Embolization (\%) & 0 & 3 \\
Failure of Non-operative Therapy(\%) & 0 & 6 \\
Deep Venous Thrombosis (\%) & 0 & $7 / 35(20)$ \\
\hline Pulmonary Embolus (\%) & 0 & $1 / 35(3)$
\end{tabular}

ISS = Injury Severity Score

$I C U=$ Intensive Care Unit

PAD = Post Admission Day

DVT $=$ Deep Venous Thrombosis

\section{Discussion}

Multi-system trauma is a major risk factor for the development of a DVT. In patients without thromboprophylaxis, the overall incidence exceeds $50 \%$ and the rate of proximal limb DVTs approaches $18 \%[3,7,8]$. Although an isolated DVT is rarely life-threatening, subsequent PE often carry significant morbidity and mortality. Pulmonary embolism is estimated to be the third leading cause of death in trauma patients who survive beyond the first day [3,9-11]. While non-operative management of hepatic trauma appears to be safe in up to $98 \%$ of hemodynamically stable patients, the optimal timing of pharmacologic DVT prophylaxis is unclear [2]. There is often a delay in the administration of chemical prophylaxis in an attempt to prevent recurrent liver hemorrhage, and therefore the perceived risk of converting non-operative candidates into operative cases. As a result, physicians must balance the risk of re-bleeding with the development of a venous thromboembolism.

In this study population, only 2 patients failed non-operative observation. Both had grade 5 hepatic injuries that hemorrhaged prior to initiating DVT prophylaxis. As expected, patients with lower grade injuries were more likely to receive early prophylaxis compared to those with high grade hepatic injuries. Approximately $80 \%$ of patients with high grade injuries received delayed DVT prophylaxis. Considering the rare occurrence of non-operative treatment failure, this difference is particularly striking because only $34 \%$ of patients with low grade injuries were delayed in their chemical prophylaxis.

A significant subset of patients (33\%) received no pharmacologic DVT prophylaxis. This group possessed a mean hepatic injury grade that was nearly identical to the delayed prophylaxis cohort (3 versus 2.9 respectively). They did however have a significantly shorter hospital LOS ( 8 versus 26 days respectively). The most likely explanation for the lack of prophylaxis in this group was that these patients were expected to receive 'delayed' prophylaxis but were discharged before chemical prevention was initiated. We view this as a treatment failure by our trauma services. These patients displayed no clinically significant DVTs or PEs during their hospital admission. We believe this is a direct result of their early ambulation. Because outpatient follow-up data was not available, the actual number of patients in any particular group who were discharged home and later developed a DVT or PE is unknown.

Neither failure in non-operative observation, nor increases in blood transfusions were observed in patients who received early DVT prophylaxis. Although limited patient numbers and an injury grade bias across study groups made it difficult to draw definitive conclusions, 
this study suggests that early pharmacologic DVT prophylaxis may be safe in patients with blunt liver trauma. This cannot be confirmed elsewhere in the literature because the only publication to describe a comparable patient population did not assess the use or timing of pharmacologic DVT prophylaxis [2]. It did appear that the majority of their patients who failed non-operative therapy had grade 4 and 5 injuries however [2]. It is also important to note that had our study employed prospective ultrasound screening for all trauma patients (rather than screening for those patients with a "high" clinical suspicion for DVT), the rates of DVT in the delayed and no prophylaxis cohorts may have been even more substantial.

\section{Conclusion}

In summary, 98\% of our patients underwent successful non-operative management of blunt hepatic injuries. Patients with low grade injuries generally received pharmacologic DVT prophylaxis early in their hospital admission. Most importantly, early pharmacologic DVT prophylaxis did not result in increased blood transfusion requirements or non-operative failures. This was consistent regardless of the injury grade. As a result of this data, we are now beginning to standardize early prophylaxis in our patients with blunt hepatic trauma. We believe that delays in pharmaceutical prevention place patients at a significantly increased risk for venothromboembolic events. This risk approximates $18 \%$ if prophylaxis is delayed more than 48 hours after admission. To confirm these observations, a multicenter randomized controlled trial is planned.

\section{Competing interests}

The authors declare that they have no competing interests.

\section{Authors' contributions}

ID - Study design, data analysis, manuscript \& editing.

CGB - Data analysis, manuscript writing \& editing.

LRR - Data analysis \& manuscript writing.

DP-G - Data analysis.

DB - Data analysis \& editing.

PS - Data analysis \& manuscript writing.

CS - Data analysis \& manuscript writing.

DFS - Data analysis.

MvW - Data analysis, manuscript writing \& editing.

JHK - Data analysis, manuscript writing \& editing.

\section{Acknowledgements}

This manuscript was presented at the Trauma Association of Canada conference in Banff, Alberta

\section{References}

I. Matthes G, Stengel D, Seifert J, Rademacher G, Mutze S, Ekkernkamp $A$ : Blunt liver injuries in polytrauma: results from a cohort study with the regular use of whole-body helical computed tomography. World J Surg 2003, 27: I I24-30.

2. Pachter HL, Knudson MM, Esrig B, Ross S, Hoyt D, Cogbill T: Status of nonoperative management of blunt hepatic injuries in 1995: a multicenter experience with 404 patients. J Trauma 1996, 40:3I-8.

3. Geerts WH, Code KI, Jay RM, Chen E, Szalai JP: A prospective study of venous thromboembolism after major trauma. $\mathrm{N}$ Engl J Med I 994, 33 I: 160 I-6.

4. Geerts WH, Jay RM, Code KI, Chen E, Szalai JP, Saibil EA: A comparison of low-dose heparin with low-molecular-weight heparin as prophylaxis against venous thromboembolism after major trauma. N Engl J Med 1996, 335:70I-7.

5. Datta I, Findlay C, Kortbeek JB, Hameed SM: Evaluation of a regional trauma registry. Can J Surg 2007, 50:210-13.

6. Croce MA, Fabian TC, Kudsk KA, Baum SL, Payne LW, Mangiante EC, Britt LG: AAST organ injury scale: correlation of CT-graded liver injuries and operative findings. J Trauma 1991, 31:806-I2.

7. Kudsk KA, Fabian TC, Baum S, Gold RE, Mangiante E, Voeller G: Silent deep vein thrombosis in immobilized multiple trauma patients. Am / Surg 1989, I 58:515-9.

8. Geerts WH, Heit JA, Clagett GP, Pineo GF, Colwell CW, Anderson FA: Prevention of venous thromboembolism. Chest 200I, I 19:132S-175S.

9. Acosta JA, Yang JC, Winchell RJ, Simons RK, Fortlage DA, Hollingsworth-Fridlund $P$ : Lethal injuries and time to death in a level $I$ trauma center. J Am Coll Surg 1998, 186:528-33.

10. O'Malley KF, Ross SE: Pulmonary embolism in major trauma patients. J Trauma 1990, 30:748-50.

II. Rogers FB, Shackford SR, Wilson J, Ricci MA, Morris CS: Prophylactic vena cava filter insertion in severely injured trauma patients: indications and preliminary results. J Trauma 1993, 35:637-4I.
Publish with BioMed Central and every scientist can read your work free of charge

"BioMed Central will be the most significant development for disseminating the results of biomedical research in our lifetime. "

Sir Paul Nurse, Cancer Research UK

Your research papers will be:

- available free of charge to the entire biomedical community

- peer reviewed and published immediately upon acceptance

- cited in PubMed and archived on PubMed Central

- yours - you keep the copyright

Submit your manuscript here:

http://www.biomedcentral.com/info/publishing_adv.asp
BioMedcentral 